\title{
Grid integration of DC fast-charging stations for EVs by using modular li-ion batteries
}

\author{
Gjelaj, Marjan; Hashemi, Seyedmostafa; Træholt, Chresten; Andersen, Peter Bach
}

Published in:

I E T Generation, Transmission and Distribution

Link to article, DOI:

10.1049/iet-gtd.2017.1917

Publication date:

2018

Document Version

Peer reviewed version

Link back to DTU Orbit

Citation (APA):

Gjelaj, M., Hashemi, S., Træholt, C., \& Andersen, P. B. (2018). Grid integration of DC fast-charging stations for EVs by using modular li-ion batteries. I E T Generation, Transmission and Distribution.

https://doi.org/10.1049/iet-gtd.2017.1917

\section{General rights}

Copyright and moral rights for the publications made accessible in the public portal are retained by the authors and/or other copyright owners and it is a condition of accessing publications that users recognise and abide by the legal requirements associated with these rights.

- Users may download and print one copy of any publication from the public portal for the purpose of private study or research.

- You may not further distribute the material or use it for any profit-making activity or commercial gain

- You may freely distribute the URL identifying the publication in the public portal

If you believe that this document breaches copyright please contact us providing details, and we will remove access to the work immediately and investigate your claim 


\title{
Grid Integration of DC Fast-Charging Stations for EVs by using Modular Li-ion Batteries
}

ISSN 1751-8687

Received on 1st December 2017

Revised 20th April 2018

Accepted on 17th May 2018 doi: 10.1049/iet-gtd.2017.1917 www.ietdl.org

\author{
Marjan Gjelaj ${ }^{1} \bowtie$, Seyedmostafa Hashemi ${ }^{1}$, Chresten Træholt ${ }^{1}$, Peter Bach Andersen ${ }^{1}$ \\ ${ }^{1}$ CEE-Department of Electrical Engineering, Technical University of Denmark, 2800 Kgs. Lyngby, Denmark \\ 四 E-mail: margje@elektro.dtu.dk
}

\begin{abstract}
Widespread use of electric vehicles (EVs) requires investigating impacts of vehicles' charging on power systems. This paper focuses on the design of a new DC fast charging station (DCFCS) for EVs combined with local battery energy storages (BESs). Due to the BESs the DCFCS is able to decouple the peak load demand caused by multiple EVs and decrease the installation costs as well as the connection fees. The charging system is equipped with a bidirectional AC/DC converter, two lithium-ion batteries and a DC/DC converter. The introduction of BES within the DCFCSs is investigated with regards to operational costs of the charging stations as well as the ability of a BES to mitigating negative impacts on the power grid during congestion hours. The proposed solution is shown to reduce not only the installation costs but also the charging time and it facilitates the integration of fast chargers in existing low voltage (LV) grids. A cost-benefit analysis (CBA) is performed to evaluate the financial feasibility of BES within the DCFCSs by considering the installation costs, grid connection costs and battery life cycle costs.
\end{abstract}

\section{Introduction}

INCREASED focus on sustainable transportation and $\mathrm{CO} 2$ reduction leads to large investments into electric vehicle (EV) technology from the major car producers. Rising numbers of EVs in major cities and widespread rollout of EV charging infrastructures are introducing new high power loads to distribution system operators (DSOs). In recent years environmental concerns and advances in battery technology drive the rapid development of electrical transportation [1][3]. In a sustainable city [4], with an increasing amount of electric vehicles, a lot of concern is raised on EV grid integration as well as a tariff system that allows to control the EVs charging demand [5]-[6]. The EN /IEC 61815 and automotive engineers in U.S. SAE J1772 have proposed the EV charging modes and the maximum current delivered both on alternating and direct current (AC and DC).

Currently, the public charging stations in the major European cities are providing 7 - $43 \mathrm{~kW}$ [7], which with the current EV models and charging stations require more than an hour to cover a range of $150 \mathrm{~km}$.

Considering the growing number of EVs over the next 10 years [8], appropriate fast charging infrastructures are anticipated to supply the future EV power demand. Therefore, the widespread use of EVs requires investigating impacts of vehicles' charging on the distribution grids. So far, extensive study has focused on optimizing the EV penetration and the charging infrastructure. An optimal approach is proposed in [9] with a day-ahead energy planning of EVs by scheduling different EVs scenarios. Some authors are focused on innovative schedule price policies [10], in order to avoid the peak load and the waiting time at the fast charging stations (FCSs). Instead, reference [11] suggests a hierarchical game approach on the electricity price strategy by improving the reliability of the power systems and the economic profits of the FCSs. However, the integration of the FCSs involves different aspects of the power systems, such as the network losses, overloading of distribution transformers during the peak demand and the negative impact on the voltage profile. Reference [12] proposes an optimal sizing and siting of the charging infrastructures in order to reduce the network losses and improve the voltage profile. In [13] an optimization process is made of the sizing and siting the EV charging stations by minimizing the charging station costs. In addition, [14] suggests a spatially explicit agent-based model that determines the spatial distribution of chargers by introducing load shifting of the EV demand. Another solution in [15] recommends a scheduling strategy of the FCs by reducing the impact in low voltage (LV) grid. Alternatively, another study proposes to use stationary batteries as buffer between the grid and the charging stations in order to limit the peak consumption [16]. Likewise, [17] introduces an optimal size of battery energy system (BES) in the FCSs, by using a dynamic traffic model in order to minimize the FCSs operational costs and the BES size.

Consequently, it is important to design appropriate fastcharging stations for EVs, which are able to meet the expected demand. Designing appropriate charging infrastructures require not only meeting the EVs demand at any time of a day, 
but also minimizing the installation costs as well as the grid reinforcement costs. In many DSO/LV network load is limited to $500 \mathrm{~kW}$ [18]. Despite the fact that recent papers have introduced the FCs and BESs, more work is required on the DC fast charging stations (DCFCSs) design and the BES size by considering the increasing EVs market penetration [8]. Additionally, the integration of the BESs within the FCSs have to take into account the evolution of the power electronics, as well as the new Li-ion battery technologies [19] and the annual cost reduction of batteries [3].

In this paper, the authors attempt to determine a design criteria including a concept with two BESs within the DCFCSs. In particular, we propose a novel design of a stationary twin BESs that allows partial decoupling between DCFCSs and LV grid as shown in Fig. 1. The operation of the DCFCS is based on dynamic charging systems of the BESs that allow one of the batteries (BES2) to be charged from the grid while the other (BES1) is charging an EV and vice versa. The study aims to determine an optimal size of the DCFCS and BESs by taking into account different EVs charging demand. Furthermore, the proposed solution allows to reduce the charging time as well as the power required from the grid in order to avoid grid reinforcement costs of the DCFCSs. In conclusion, compared with the published works, the main contributions of in this paper are the following:

- A statistical method is proposed to determine the expected EV charging demand by using different commercial EVs. According to the EV demand, an optimal design of the BES and DCFCSs are implemented by using real BES data from the datasheet within the simulations.

- A planning method is presented for the integration of different DCFCSs within the power systems in order to minimize grid connection costs by using BESs.

- Finally, a cost-benefit analysis (CBA) is performed to evaluate the financial feasibility of BES within the DCFCSs by considering the battery life cycle and replacement costs.

Numerical simulations are conducted to illustrate the implementation of the proposed method.

The paper is organized as follows. Charging modes for EVs are described in Section 2. Section 3 discusses the methodology used to design and control the BES within the DCFCs. An optimal BES control strategy with a CBA are discussed with the results in Section 4 and the conclusions in Section 5.

\section{EV Charging Modes}

There are two main approaches for charging EVs. The first one is to use on-board EV's charger and connect it to the AC grid. The second is to charge the EV via an off-board charger using DC. Existing charging modes for EVs are specified by the standard IEC 61851 for "electric vehicle conductive charging system". The standard describes both on-board and off-board EV chargers and distinguishes between four charging modes: 1, 2, 3 and 4 [7]. Mode 4 is the only mode that allows connection to DC. The requirements for control and communication of both DC charger and EV can be found in part 23 and 24 of IEC 61851 [7] and IEC 15118 [20]. By using mode 4 , the charging time can be reduced to $30-45$ minutes for charging an EV battery of $30 \mathrm{kWh}$ up to $80 \%$ state-of-charge $(\mathrm{SoC})$ with a power of $50 \mathrm{~kW}$. Table 1 summarizes the main characteristics of these charging modes with their respective maximum power according to IEC 61851 [7] and IEC 62196 [21]. The IEC 62196 applies to plugs, socket-outlets, and connectors based on conductive charging. The current AC charging infrastructure has proved its ability to deliver the charging services safely and reliably. Most of the existing stations are operated in modes 2 and 3 in order to lower the infrastructure costs, reduce the impact on the grid and align with international standards. However, using these modes lead to the limitations on the transferred power as shown in Table 1 and therefore longer charging times.

Table 1 Charging mode according to IEC 61851 [7]

\begin{tabular}{lccc}
\hline Mode & Phase & $\begin{array}{c}\text { Maximum } \\
\text { current }\end{array}$ & $\begin{array}{c}\text { Minimum } \\
\text { voltage }\end{array}$ \\
\hline Mode 1 & 1 & $16 \mathrm{~A}$ & $250 \mathrm{~V}$ \\
(AC) & 3 & $16 \mathrm{~A}$ & $480 \mathrm{~V}$ \\
Mode 2 & 1 & $32 \mathrm{~A}$ & $250 \mathrm{~V}$ \\
(AC) & 3 & $32 \mathrm{~A}$ & $480 \mathrm{~V}$ \\
Mode 3 & 1 & $32 \mathrm{~A}$ & $250 \mathrm{~V}$ \\
(AC) & 3 & $250 \mathrm{~A}$ & $690 \mathrm{~V}$ \\
Mode 4 & - & $400 \mathrm{~A}$ & $1500 \mathrm{~V}$ \\
(DC) & - & &
\end{tabular}

The mode 3 takes around 1 hour to charge an EV with $20 \mathrm{kWh}$ battery up to $80 \%$ of its SoC with charging power of $22 \mathrm{~kW}$. In addition, the $\mathrm{AC}$ chairing time may cause congestion with the parking lots, especially in urban areas. In order to solve those issues the special attention should be brought to mode 4 with off-board charging in DC. The IEC 62196 standard allows for DC charging up to 400 A with power from 50 to $600 \mathrm{~kW}$ in CHarge de MOve (CHAdeMO) "mode" and Combined Charging System (Combo) "mode". The following DC charging stations are currently available on the market: ABB $50 \mathrm{~kW}$ with combo in LV, 62.5 kW by CHAdeMO in $\mathrm{LV}$ and $120 \mathrm{~kW}$ Tesla system with connection on medium voltage (MV) side (charger-to-grid connection). The advantages of mode 4 are reduced charging time and higher efficiency due to the absence of additional converter. However, the high power demand (especially more after 100$150 \mathrm{~kW}$ ) from such charging stations requires a strong distribution grid and typically a connection to MV level with a specifically designated transformer. This creates obstacles in regards to space and investment cost for the DC charging stations.

\section{Methodology}

\subsection{Integration of the BES into DCFCS}

Combining DCFCS and BES can provide a reliable solution to mitigate unfavorable side effects on the grid. The EVs' load demand can be partially reduced through this setup by supporting the system operation in terms of power decoupling through the BESs. The solution also contributes the improvement of grid regulation and defers costly network reinforcement [22]-[23]. Lastly, this solution has the potential of providing various ancillary services to support the power system operation, such as primary frequency control or voltage control [20],[24] The DCFCS is not only an infrastructure for EVs recharge, but also a crucial solution to integrate them into smart grids, which interconnects the main 
grid with various distributed renewable energy resources and storage [8]. Another factor that needs to be taken into account is the cost reduction of the lithium-ion batteries. The annual cost reduction of $\mathrm{Li}$-ion batteries can be reduced up to $8 \%$ [3]. This represents a great opportunity for integrating the penetration of EVs and smart charging stations. Therefore, possible scenarios of the BES within the DCFCS can be implemented in order to provide different ancillary services for flexible loads such as EVs [24]-[25]. In EVLabDK [26] and the project EnergyLab Nordhavn [4], BESs data was collected and analysed by using our laboratory facilities. A model for optimal operation of the BES in the distribution grid was developed. Communications management and compatibility of devices with the current technologies were considered according to IEC61850 [27] to evaluate the performance and interoperability of all those systems. Particularly, advancement in power electronics interfaces development, as well as battery storage technology, will be decisive factors. In this paper, proposed DCFCS focuses on a specific power electronic architecture consisting of a bidirectional $\mathrm{AC} / \mathrm{DC}$ converter, $\mathrm{DC} / \mathrm{DC}$ converter and two BESs. By combining these elements, the EV battery will be charged from the first BES in order to support its demand. When size is properly designed, the AC/DC converter will recharge the second BES while the vehicle is being charged. In this case, with a fully charged second BES, the DCFCS can support the next user to recharge the EV with the same charging rate for 10 minutes. In the meantime, the first battery that was discharged earlier on will immediately be charged through the AC/DC converter. Once congestion or batteries malfunction occurs, the EV will be charged directly by the grid through the AC/DC as shown in Fig. 1.

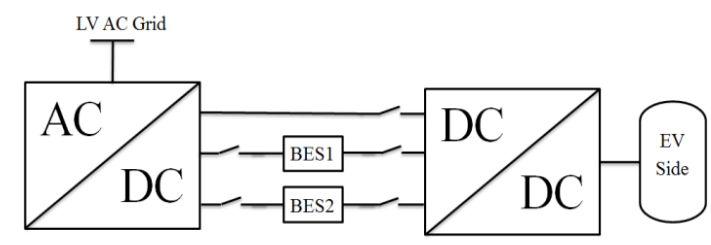

Fig. 1. DCFCS in mode 4 in LV grids with BESS

\subsection{Optimal Design of the DCFCS}

In the following batteries, BES1 and BES2 converters $\mathrm{AC} / \mathrm{DC}$ and $\mathrm{DC} / \mathrm{DC}$ and the EV have been designed by using models available in Matlab/Simulink. For determining the optimal operation of the DCFCS, a large amount of data must be known, such as the arrival time, EVs SoC and the charging duration. The local grid provides the battery-charging power and it can be expressed as [28]:

$$
P_{\text {grid }}=\frac{1}{\eta_{\text {conv }}} \cdot I_{B E S} \cdot\left(u_{o c} \cdot S o C_{0}+I_{B E S} \cdot \sum R_{c e l l}\right)
$$

The $I_{B E S}$ is the BES current measured in ampere (A) and it is given by the $\mathrm{AC} / \mathrm{DC}$ converter, $u_{o c}$ is open circuit voltage (V), the $R_{\text {cell }}$ is the resistive characteristics (Ohm) caused by the sum of the internal contact of individual cells. $\eta_{\text {conv }}$ represents the efficiency (\%) of the converter, and it is estimated at $95 \%$. The charging station will have one or more charging slots, and each of them can be connected to the LV grid with a minimum power of $22 \mathrm{~kW}$ required form the grid in AC. The EVs load demand generated by the EVs changes during the day, and it is considered as a random variable. To make the power demand study more realistic, the following steps are made:

1. Initial EV SoC $\left(S o C_{E V S}\right)$ is estimated between $20 \%-50 \%$ with a mean of $35 \%$;

2. Battery capacity $\left(B_{c}\right)$ of the EV is between $5 \mathrm{kWh}-60$ $\mathrm{kWh}$ with a mean of $32.5 \mathrm{kWh}$;

3. The $u_{o c}$ is the open circuit voltage of each BES which has linear relationship to SoC;

4. The charging curves of the EVs are based on random arrival charging time

The current DC off-board charger has a voltage of $V_{R E F}=500 \mathrm{~V}$. The EV battery pack considered for the simulation is $20 \mathrm{kWh}$. The energy exchanged between the BES and the EV varies from $25 \%$ to $100 \%$ SoC as shown in Figure 2. The resistance is considered with base value $\sum R_{\text {cell }}(20 \mathrm{kWh})=98 \mathrm{~m} \Omega$ from the datasheet [26], [29].

$$
\sum R_{\text {cell }\left(E_{\text {bet }}\right)}=\sum R_{\text {cell }} \cdot\left(B_{c}\right)
$$

In this case study, the most important factors to take into account are the available power from the grid side and the battery charging process. The $S o C(t)$ of batteries can be calculated based on the coulomb counting [28]:

$$
\operatorname{SoC}(t)=\operatorname{SoC}_{i}+\frac{\Delta t}{Q_{b a t}} \cdot \sum_{\tau=0}^{t} I_{B E S, \tau}
$$

where $Q_{b a t}$ is the coulomb count of the battery capacity in ampere-second and it is used within the numerical time step integration. The charging is completed, when $\mathrm{SoC}=\mathrm{SoC}_{80 \%}$. $I_{B E S}(t)$ is the battery current in ampere and $S_{0} C_{0}$ corresponds to the $S o C$ (in \%) of the battery at the beginning of the simulation $\left(t_{0}\right)$ [28]. The $I_{B E S}(t)$ can be expressed as:

$$
I_{B E S}(t)=k_{2}(t) I(t)+k_{1} I(t)+k_{0}
$$

where $k_{0}, k_{1}, k_{2}$ are constant values obtained from the datasheet [29]. The BES terminal voltage $V_{B E S}$ is a sum of $u_{o c}$ and it drops across the internal resistance, and it has a linear relationship between $S o C$ and $u_{o c}$ as shown in (5);

$$
V_{B E S}(t)=u_{o c}(S o C)+I_{B E S} \cdot \sum R_{\text {cell }}
$$

The size of each BES can be calculated as: 


$$
\left\{\begin{array}{l}
B E S_{1}=B E S_{2}=C_{B E S} \cdot B_{c} \\
C_{B E S}=S o C_{80 \%}-S o C_{E V S}-S o C_{10 \%}
\end{array}\right.
$$

$C_{B E S}$ represents the probabilistic coefficient of the BESs and the $S o C_{10 \%}$ is the usable EVs battery. According to the tests performed in the EV laboratory [26] only $90 \%$ of the nominal capacity is used as work capacity, and the remaining $10 \%$ will be used over time in proportion to the battery degradation. $\mathrm{SoC}_{80 \%}$ is the fixed constraint for charging EVs up to their $80 \%$ SoC. The limitation of the charging process up to $80 \%$ is due to the battery management system (BMS) of the cars which will drastically reduce the charging power and increase the charging time until the end of the charging process. In the equation (6), each BES is $11.4 \mathrm{kWh}$, and both have been oversized of $14.25 \mathrm{kWh}$ in order to maximize the BES lifetime cycles according to a maximum depth of discharge (DoD) which cannot exceed $75 \%$ [30] as shown in Figure 2. The $B E S_{D L}$ is the BES degradation life expressed per year as [30]:

$$
\left\{\begin{array}{l}
B E S_{D L}=\frac{C_{P Y} \cdot \Delta_{T e}^{-1}}{B E S_{C D o D}} \\
B E S_{C D o D}=\alpha_{D L} \cdot D o D^{-\beta_{D L}}
\end{array}\right.
$$

$C_{P Y}$ represents the number of cycles per year of the BESs under a predefined variable work temperature $\Delta_{T e}=0,9814$ [31]-[32]. $B E S_{C D o D}$ is the relation between the number of cycles given by the manufacture and the DoD. $\alpha_{D L}$ is the maximum life cycles with DoD at $100 \%$ [32], and $\beta_{D L}$ is the interpolation value of the lithium-ion battery which is 1.61 [32]. For Lithium Nickel Manganese Cobalt Oxide (NMC) with 5000 Cycles calculated with $80 \%$ DoD $\alpha_{D L}$ corresponds to 3500 cycles [32]. The cycles ageing per year can be expressed based on end of life (EOL) criterion. EOL is considered when $20 \%$ capacity fade $\left(C_{F}\right)$ is reached [32]. According to (7) the BES capacity fade $\left(B E S_{C F}\right)$ in $[\%]$ per year can be calculated as:

$$
B E S_{C F}=B E S_{D L} \cdot C_{F}
$$

The charging/discharging characteristics of Li-ion battery are considered in this paper in order to size the AC/DC $\mathrm{DC} / \mathrm{DC}$ converters. According to (6) with a discharge rate of $6 \mathrm{C}$ [29] the DC/DC converter is $70 \mathrm{~kW}$. Instead, the AC/DC converter is $50 \mathrm{~kW}$ with BES charging rate of $4.62 \mathrm{C}$ [29]. With 6C discharge rate the $\mathrm{DC} / \mathrm{DC}$ converter is designed to charge EVs in less than 10 minutes. In addition, the design model allows partial decoupling between DCFCS and LV grid by reducing the required grid power by $28.57 \%$.

\subsection{DCFCS Modelling and Control}

The SOCs of the batteries, $S o C_{B E S 1}$ and $S o C_{B E S 2}$ are determined by measuring the voltage on the battery terminals $V_{B E S}$. The reference voltage $V_{B E S}$ establishes the discharge curve of the BES within the nominal operating area. Fig. 2a shows the operation limits considering three levels: normal, low and high-level SoC. Fig. $2 \mathrm{~b}$ represents the control system used between BES and EV.
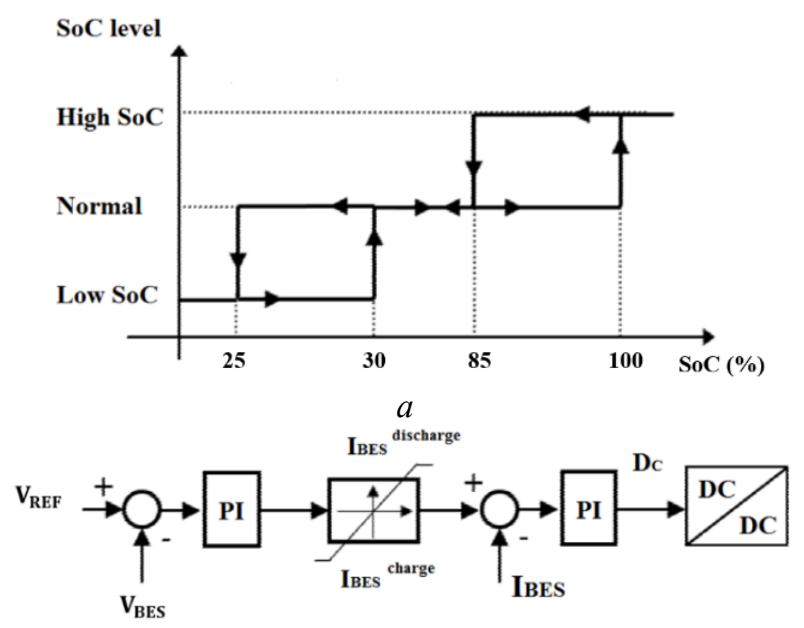

$b$

Fig. 2. BES SoC level and control system

(a) SoC level determination through the $V_{B E S}$, (b) BES control system

In order to maintain a constant voltage on the EV side, the measured voltage $V_{B E S}$ is compared at the end with a reference voltage $V_{R E F} . V_{R E F}$ is used as a linear loop of the DC/DC converter for the dynamic limitation of the BES current and to determine the end of the SoC levels. The PI controller uses the $I_{B E S}$ as a current reference of the BES to control the transferred power from the EV. Instead, the $I_{B E S}$ is limited in function to the discharging rate $6 \mathrm{C}$. The $\mathrm{PI}$ controls the duty cycle of the BES DC/DC converter within the set parameters. When the $S O C_{B E S}$ reaches $25 \%$ the BES will stop to transfer power to the vehicle. The AC/DC converter will recharge each BES with $50 \mathrm{~kW}$ and a charging rate of $4.62 \mathrm{C}$.

\subsection{Cost-benefit analysis methodology}

Designing an appropriate DC-charging station in low voltage (LV) is important to avoid the connection in MV and minimize the operating costs. In addition, DSOs are focused on minimizing losses and reducing the size of the electrical lines to mitigate the network congestion. This section presents the methodology applied for CBA comparing BESs in conjunction with a charging stations [33]-[34].

The first method uses the BESs within the charging stations with the connection to LV grids and the second method the charging stations will be connected to the MV grid. The main objective of the CBA is to establish the infrastructure costs and lifetime of different storage that make battery installations profitable. In particularly if it is convenient for the Electric Vehicle Supply Equipment Operator to integrate batteries within the DC charging stations. The economic analysis of investments is a crucial stage especially if there is not a clear perspective of the EV market penetration [34]-[35]. The key components of an investment are: the capital cost or initial investment, the 
interest rate, the return on the investment and the lifetime of the investment. In this case, two methods have been used.

3.4.1 The method 1: does not consider the time value of the money over the years and interests. The payback period $(P B P)$ is the amount of time necessary to recover the capital investment from the net cash flow and is calculated as [35]:

$$
P B P=\frac{\text { cost of investment }}{\text { annual revenue }}
$$

The internal rate of return (IRR) is the reciprocal of the $P B P$ and it is generally expressed as a percentage [35]:

$$
I R R=\frac{\text { annual revenues }}{\text { cost of investment }}
$$

The $I R R$ is the discount rate at which the net present value of all cash flows is equal to zero. The interest are considered equal to zero.

3.4.2 The method 2: considers the time value of the money over the years and interests. The net present value $(N P V)$ is the difference between the present value of cash inflows and the present value of cash outflows. It is one of the most frequent investment criteria for deciding on a given investment. The $N P V$ is calculated as [2], [35]:

$$
N P V=\sum_{t=1}^{T} \frac{B_{t}}{(1+r)^{t}}-\sum_{t=1}^{T} \frac{C_{t}}{(1+r)^{t}}-C_{0}
$$

The $N P V$ is the sum subtracted from future benefits minus costs as shown in (11). $B_{t}$ and $C_{t}$ represent the benefit (revenue) and the net cash inflow during the investment period $T$, respectively, $r$ is the discount rate (interest) and $C_{0}$ stands for the total initial investment costs. The $N P V$ is used to analyse the profitability of a planned investment or project, and any project with a positive $N P V$ can be considered.

In this paper, the method 2 is used for the financial assessment of BES projects as used in [33]-[34]. If the NPV is higher than zero, the project is valid since the revenues are enough to pay the interest and to recover the initial capital cost before the end of the investment life. If the $N P V$ equals zero, the balance occurs at the end of the life, but the investment is scarcely attractive. Negative $N P V$ means investment not profitable for the investors. Similar projects can be compared through the parameter of the ratio between the $N P V$ of the project and the related investment (NPVbenefits/NPV-costs) commonly called "Benefit-Cost Ratio" [2], [35]. This method is used for evaluating and comparing the economic performance of one or more investments.

The benefit-cost ratio $(B / C)$ and can be expressed as:

$$
B / C=\frac{N P V(\text { Benefits })}{N P V(\operatorname{Cos} t s)}=\frac{\sum_{t=1}^{T} \frac{B_{t}}{(1+r)^{t}}}{\sum_{t=1}^{T} \frac{C_{t}}{(1+r)^{t}}+C_{0}}
$$

$B / C$ is largely employed to estimate the cost of a project compared to the benefits derived, seeking to determine an optimal approach to achieve benefits. When it comes to monetary decisions, where the discount rate /interest $r$ is considered, the CBA estimates the monetary value of the costs, and the monetary value of the benefits, and compares them to evaluate whether the decision is worth taking.

\subsection{Cost and Revenue Calculation}

Two cases are considered for the CBA in the current paper. Case A - DCFCS with BES and Case B - DCFCS with a connection to $\mathrm{MV}$ grid.

\subsubsection{Case $A$ - DCFCS with BES: the annual} costs and benefits associated to the case A - BES within the charging stations are calculated taking into account the infrastructure costs and as benefits the consumption of electricity.

The total annual cost for case $\mathrm{A}\left(T A C_{A}\right)$ is:

$$
T A C_{A}=C_{A}+\operatorname{In}+O \& M
$$

where $C_{A}$ includes the component costs: the chargers costs $C_{C}$ and batteries costs as well as the BES life cycle costs (LCC), considering the replacement costs during investment life $T$ (7).

$$
C_{A}=\sum_{t=1}^{T} B E S_{D L, t} \cdot C_{B E S, t}+C_{C}
$$

$B E S_{D L}$ is the BES degradation life per year, $C_{B E S}$ represents the BES costs per kWh. In is the installation costs and $O \& M$ is the operation and maintenance cost. The LCC of the BES is based on the optimal (DoD) of the BESs [30], and in this case study the BES is sized to be discharged by the EV with a $\mathrm{DoD}=75 \%$. Therefore, considering a variable EVs daily demand, each EV charged by the BES involves two cycles of the BES. The BESs are oversized of $25 \%$ in order to achieve the minimum operational lifetime cost [31], [36].

The total annual revenue for case $\mathrm{A}\left(T A R_{A}\right)$ can be calculated as:

$$
T A R_{A}=(E \cdot C e) \cdot T_{A}
$$

where $E$ is the daily energy consumed in function of the EV demand, $C e$ is the cost of electricity paid by the EV users and $T_{A}$ is the total time in a year measured in days.

\subsubsection{Case B - DCFCS with a connection to MV}

grid: the annual costs and benefits associated with the case B - classic connection in MV are represented by comparing similar investments [33]. This configuration takes into account the infrastructure costs, new lines and a transformer of $500 \mathrm{kVA}$ as well as the DC charging stations and the installation costs. The benefits are the consumption of electricity.

The total annual cost for case $\mathrm{B}\left(T A C_{B}\right)$ is: 


$$
T A C_{B}=C_{B}+I n+O \& M
$$

where $C_{B}$ is the cost of components (including the chargers, lines and transformer).

The total annual revenue for case $\mathrm{B}\left(T A R_{B}\right)$ can be calculated as:

$$
T A R_{B}=(E \cdot C e) \cdot T
$$

\section{Results}

\subsection{Modelling and Control results}

The reliability of the system and the performance of the DCFCS are evaluated by a 15-minute simulation in Matlab/Simulink. A boost converter controls the DC/DC converter through the PI controllers. The boost converter helps to keep the voltage limits constant to ensure the stability of the system for each SoC of the EVs. Finally, in order to evaluate the stability of the converter, a case study has been done with an EV of $20 \mathrm{kWh}$ and SoC of $25 \%$. In addition, other studies have been performed considering the capability of the DCFCS in various scenarios with different EVs and SoCs.

4.1.1 The charging process of an EV: in the Fig. 3 every EV has a nominal capacity given by the manufacturers that represents an amount of $\mathrm{km}$ that thecar can reach with specific driving conditions. Only $90 \%$ of the nominal capacity is used as work capacity.
This system helps the user to maintain a consistent number of $\mathrm{km}$ during their use of the EV. Therefore, an EV with $20 \mathrm{kWh}$ declared by the manufacturer only $18 \mathrm{kWh}$ is used as work capacity [26]. Consequently, the discharging capacity of the BES in this case is $10 \mathrm{kWh}$ calculated as $18 \cdot(1-0.25-0.20)$, 0.25 is the EV SoC and 0.2 is the end of the charging process at $80 \% \mathrm{SoC}$ [26]. The BES is able to transfer $11.4 \mathrm{kWh}$ with a discharging rate of $6 \mathrm{C}$. Due to the communication [20] DCFCS-EV, when the EV reaches $80 \%$ SoC the DCFCS will stop charging. The power delivered from the BES, in this case, will be $10 \mathrm{kWh}$, enough to reach $80 \% S o C_{E V}$ in 10 -minutes. Fig. 3 show the discharging process of the $B E S_{1}$ through the $\mathrm{EV}$ and the power absorbed by the EV. As expected, with decreasing of the $S O C_{B E S 1}$ (Fig. 3a), the current remains constant at $140 \mathrm{~A}$ (Fig. 3d), and the voltage drops as shown in Fig. 3c. Instead, Fig. 3 b represents the active power absorbed through the EV. The converter respects the power limit of 70 $\mathrm{kW}$ with discharging rate at $6 \mathrm{C}$.

4.1.2 Charging process of the BESs: when the $B E S_{1}$ is charging an $\mathrm{EV}$ at $6 \mathrm{C}$, the $B E S_{2}$, if previously discharged, can be recharged through the grid with the AC/DC converter at $50 \mathrm{~kW}$ and a charging rate of $4.63 \mathrm{C}$ as shown in Fig. 4 . The charging process of each BES will take more time to store $11.4 \mathrm{kWh}$ because the grid power is limited to $50 \mathrm{~kW}$. As previously mentioned, the DCFCS has been designed to be used in LV grids, mainly in the cities. It can recharge each vehicle up to $80 \%$ of their $\mathrm{SoC}$ in a time period of 10 minutes.
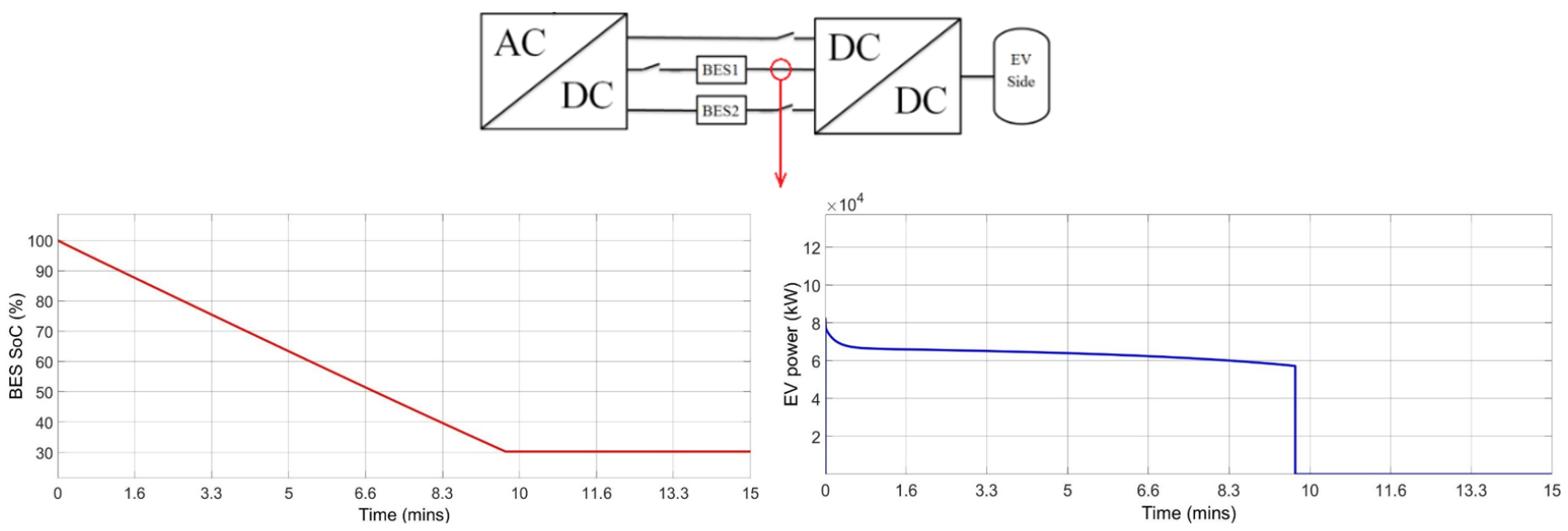

$a$

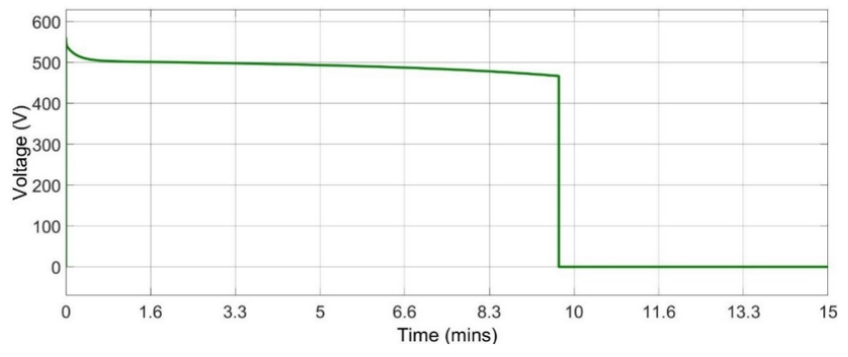

b

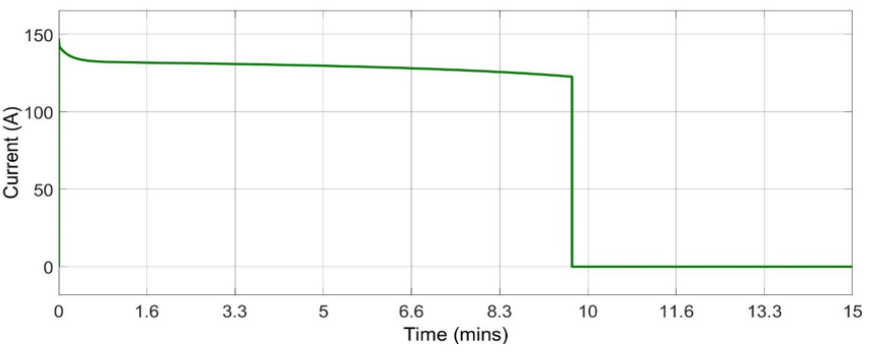

Fig. 3. Charging process of $\stackrel{c}{E V S}$

d

(a) Discharging process of the $B E S_{1}$ through the EVs, (b) Active power absorbed by EVs

(c) Discharging voltage at $6 \mathrm{C},(\mathrm{d})$ Current delivered by the BES 


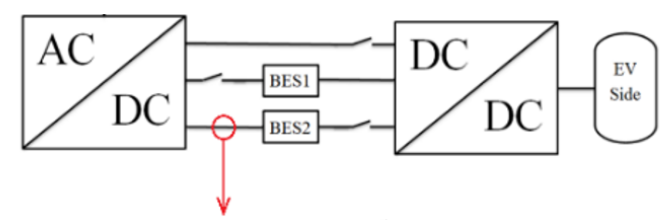

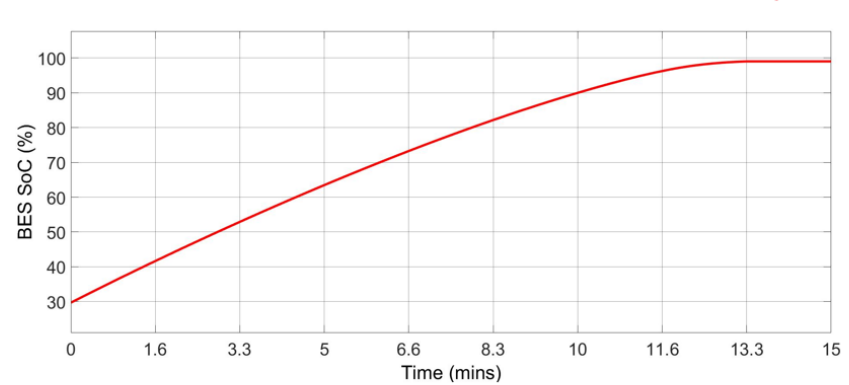

$a$

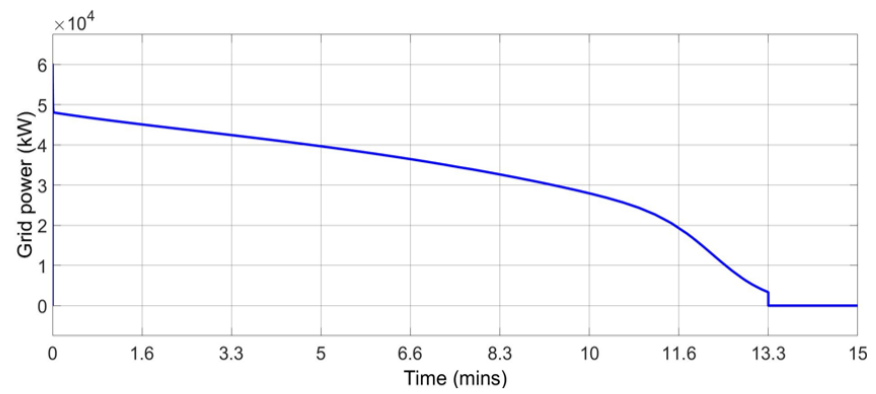

b

Fig. 4. Charging process of the BES

(a) $\mathrm{SoC}_{B E S 2}$ charging process ; (b) Active power delivered by the LV grid

4.1.3 Different scenarios of the DCFCSs: the functionality of the charging system has been evaluated on a large scale by comparing different commercial EVs. The calculations made are based on two scenarios:

1: $\mathrm{EVs}$ SoC at the beginning $=25 \%$, as shown in Fig. $5 \mathrm{a}$; 2: $\mathrm{EVs}$ SoC at the beginning $=35 \%$, as shown in Fig. 5 b;

The case studies take into account several models from 2015 to 2017 with battery pack between $16 \mathrm{kWh}$ and $60 \mathrm{kWh}$.
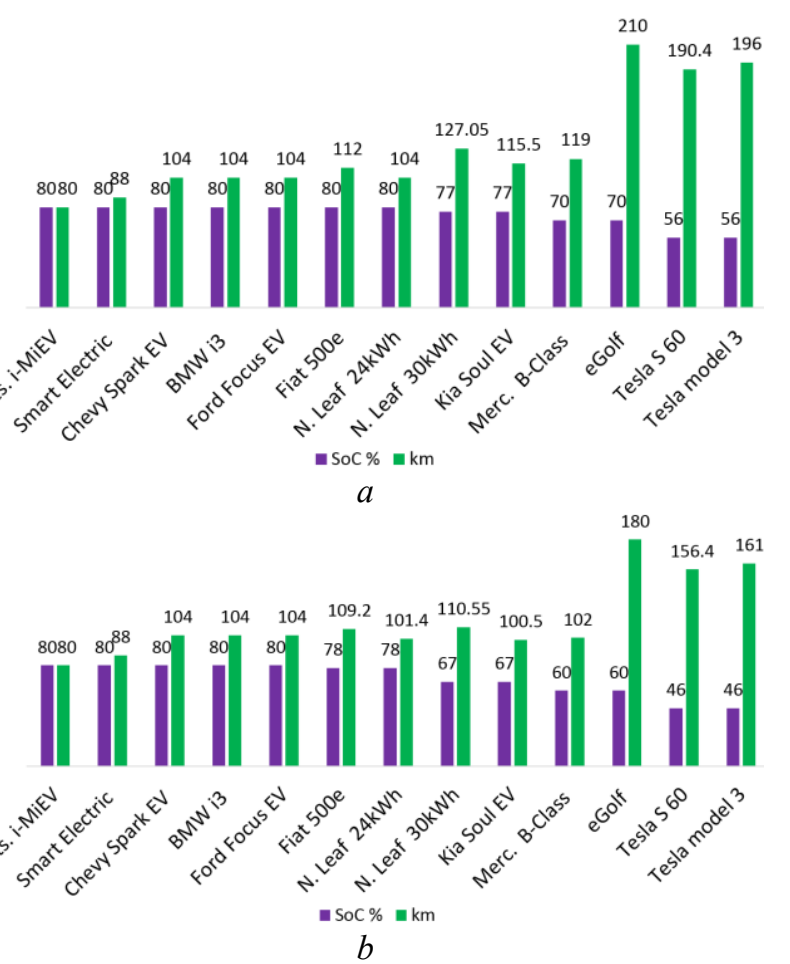

Fig. 5. EVS SoC and distance $(\mathrm{km})$ available at the end of the charging process (a) with $\mathrm{SoC} 25 \%$, (b) with $\mathrm{SoC}$ $35 \%$

As shown in Table 2, all of the EVs have a nominal battery and a usable battery for the charging system. All the EVs have been charged by the DCFCS with $70 \mathrm{~kW}$ through the BESs as shown in Fig. 5.
Table 2 Comparison of different commercial EVs

\begin{tabular}{lccc}
\hline Models (2015-2017) & $\begin{array}{c}\text { Range } \\
{[\mathrm{km}]}\end{array}$ & $\begin{array}{c}\text { Battery } \\
{[\mathrm{kWh}]}\end{array}$ & $\begin{array}{c}\text { Usable } \\
\text { battery } \\
{[\mathrm{kWh}]}\end{array}$ \\
\hline Mitsubishi i-MiEV & 100 & 16 & 14.4 \\
Smart Electric & 110 & 17 & 15.3 \\
Chevy Spark EV & 130 & 20 & 18 \\
BMW i3 & 130 & 22 & 19.8 \\
Ford Focus EV & 130 & 23 & 20.7 \\
Fiat 500e & 140 & 24 & 21.6 \\
Nissan Leaf 24 kWh & 130 & 24 & 21.6 \\
Nissan Leaf 30 kWh & 165 & 30 & 27 \\
Kia Soul EV & 150 & 30 & 27 \\
Mercedes B-Class & 170 & 36 & 32.4 \\
VW eGolf & 300 & 37 & 33.3 \\
Tesla S 60 & 340 & 60 & 54 \\
Tesla model 3 & 350 & 60 & 54 \\
\hline
\end{tabular}

\subsection{Cost-Benefit Analysis Results}

In this section, two separate layouts have been analysed to connect the DCFCS. A CBA allows us to compare two topologies of DCFCSs within the electrical grid. The first one will consider a CBA of the DCFCs in LV grids by installing lithium batteries. In this case, the benefits assessed include the decrease of grid costs in terms of grid reinforcement such as a new transformer, new lines and the connection fee in MV. The second layout considers a CBA - to justify a standard investment of the charging stations in MV grids with a new transformer and new lines. A business model situation has been made for each scenario by considering the same EV load of each method. 
4.2.1 Case A - DCFCS with BES: a combination between DCFC and BES in the residential areas could be an efficient solution to avoid the connection to MV. The DCFCS with the BESs enables the users to recharge the EVs up to $80 \%$ of their SoC with charging rate of roughly 10 minutes. The new design of the charging stations is based on the installation of two identical battery energy system (BES1 and BES2) that physically decouples DCFCS from the LV distribution grid. This system operates through successive switches of the BES

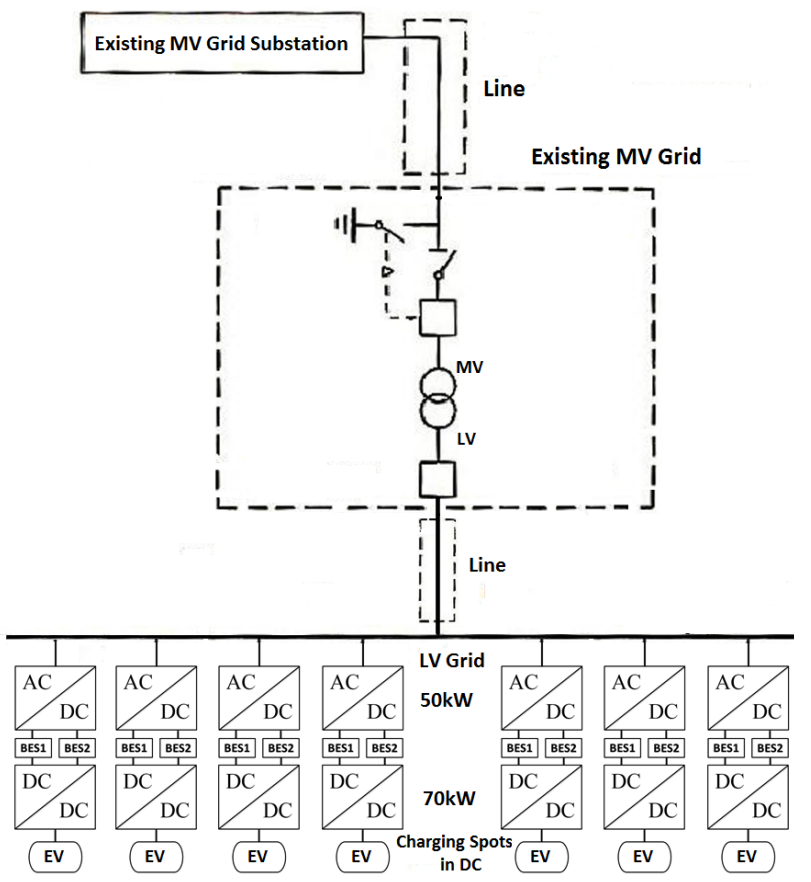

Fig. 6. Case A-DCFCS in mode 4 with BESs connected to $L V$

connections that enable one of the batteries (BES2) to be charged from the grid while the other (BES1) is charging an $\mathrm{EV}$ and vice versa as shown in simulation results. The grid configuration of the case A of the DCFCS with BESs is shown in Fig. 6. This case study considers the maximum power of the LV grids in order to prevent a connection in MV. To avoid the connection to MV and in particular, the high costs for the grid reinforcement in many cases DSO's load should not be higher than $500 \mathrm{~kW}$ [18]. In the present case, seven chargers of $50 \mathrm{~kW}$ each are able to prevent the connection to MV and thanks to the DC/DC converters; the chargers provide $70 \mathrm{~kW}$ on the $\mathrm{EV}$ side through the discharging rate of $6 \mathrm{C}$ of BESs. One of the shortcomings of such system is the battery cost and in particular the replacement costs at the end of their useful life. The CBA of the case A will consider costs of the DC charging stations, battery replacement, and the installation costs. The case A takes into account different Lithium-ion batteries with different cycles. The cases analysed are: current technology Lithium Nickel Manganese Cobalt Oxide (NMC) with 5000 and 10000 cycles and a future scenario such as Lithium Titanate Oxide (LTO) with 25000 and 30000 cycles. The energy sold to the final users in the CBA is considered as revenue in function of the EVs daily demand.
4.2.2 Case B - DCFCS with connection to MV grid: case B is a classic connection to MV when the electrical load is around $490 \mathrm{~kW}$. The choice of the DCFCS has been done according to the case A with the same EVs load demand and charging time. Accordingly, seven DC charging stations of $70 \mathrm{~kW}$ require the connection to $\mathrm{MV}$. The investment cost for the Case B is high in terms of grid reinforcement. New dedicated lines are required for the connection to $\mathrm{MV}$ and a

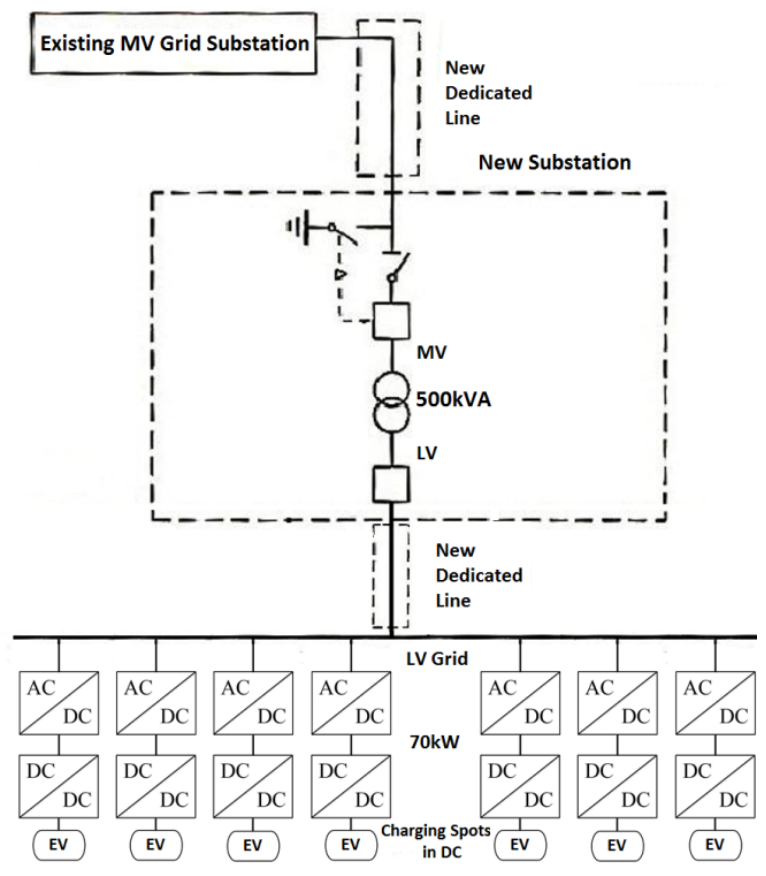

Fig. 7. Case B-DCFCS in mode 4 with a new connection to $M V$

new substation with a transformer of $500 \mathrm{kVA}$. The infrastructure costs include: the expansion of the distribution network, the new lines, DC charging stations as well as the installation costs. The energy sold to the final users is considered as revenue in function of the EVs daily recharged. Many simplifications have been assumed to compare the two CBAs such as the EVs load demand. The details of the costbenefit analysis steps will be discussed in the following section through the use of different EV scenarios. The grid configuration of the case B of the DCFCSs is shown in Fig. 7. The details of the cost-benefit analysis steps will be discussed in the following section through the use of different scenarios.

4.2.3 Financial, Market and Technology Inputs : A financial assessment for the proposed solution is presented and summarized in Fig. 8 and Table 3, 4 and 5. The financial results analyse: the payback period, internal rate of return, net present value and benefit-cost ratio. All the economic parameters are used to evaluate the financial performance of the five case studies. The financial performance of the case A, BES within the DCFCSs is dependent on the life cycle cost of the batteries and the case B, MV connection is closely linked to the EV daily demand. 


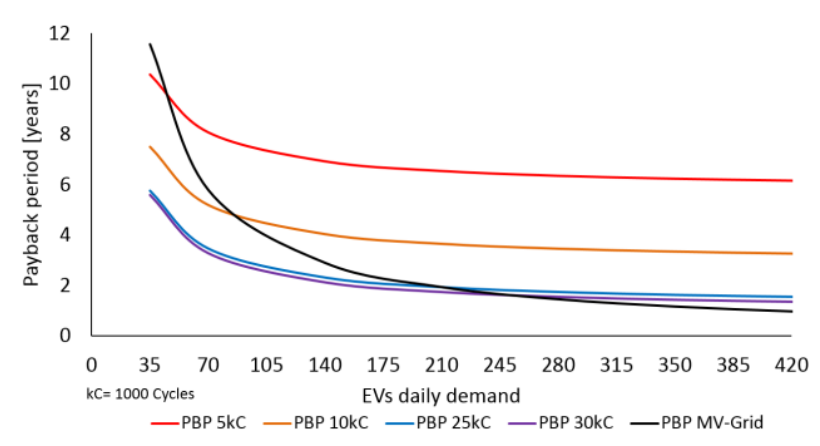

a

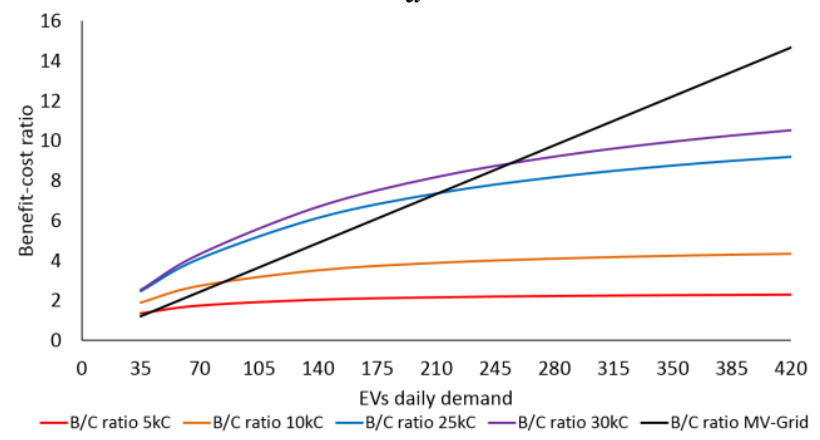

$b$

Fig. 8. Economic comparison

(a) Payback period (9) versus EVs daily demand, (b)

Benefit-cost ratio (12) versus EVs daily demand

The financial performance of the case A and case B are compared assuming the rating and costs listed:

1. Discount rate (r): 4\% [33];

2. Li-ion battery price forecast:

$200 € / \mathrm{kWh}[3]$ (2020);

3. Component costs: $1 \mathrm{~km}$ line in LV and

$1 \mathrm{~km}$ in MV and transformer

of $500 \mathrm{kVA}$ [37]-[38];

4. EV demand: $14.25 \mathrm{kWh}$;

5. DCFCS cost: $35.000 €[39]$;

6. Ce-price paid by the EV users: $0.3 € / \mathrm{kWh}$;

7. The investment life: 20 years;

Fig. 8 compares the financial performance of five case studies by using payback period (9) and the benefit-cost ratio (12) with an interest rate of 4\%. In Fig. 8, the black lines show financial performance by using the case $\mathrm{B}$ connection to $\mathrm{MV}$ grid. Instead, in the case A the red line and orange line are representing the current technology of lithium-ion battery (NMC) with 5000 and 10000 cycles. The blue line and violet line are representing future generation of the lithium battery (LTO) with 25000 or 30000 cycles. LTO has half energy density but high performance in terms of cycles. The cycles are strongly related to the battery replacement. As expected, increasing the number of battery replacements has a significant impact on the financial performance of the battery storage project as shown in the red line and orange.

Fig. 8 shows that according to benefit-cost ratio $B / C$ of the case $\mathrm{A}$ is higher than case $\mathrm{B}$ as long as the EV demand does not exceed $250 \mathrm{EVs} /$ day. Table 3, 4 and 5 summarized the main characteristics of the financial performances. Batteries with high cycles will be competitive to the case B standard configuration as shown Table 3, 4 and 5.

Table 3, 4 summarized the main cost-revenue parameters used for the financial performances of the case A. The EV daily demand is used to calculate the total annual revenue $T A R_{A}$ calculated in (15) and based on the annual energy consumed by the users. Instead, $T A C_{A}(16)$ is the investment costs including the component costs such as chargers, batteries (BES1 and BES2) and their converters as well as the installation of the chargers. Based on the EVs daily demand $T A C_{A}$ takes into account the replacements costs of the BESs which varies in function of the EVs demand and the duration of the investment. When $T A C_{A}$ and $T A R_{A}$ are defined, $P B P$ (9), $\operatorname{IRR}(10), N P V(11)$, and $B / C$ ratio (12) can be calculated as shown in the proposed methodology. Instead, BESCF represents the capacity fade per year calculated in (8).

Table 5, summarized the main cost-revenue parameters used for the financial performances of the case B. The EV daily demand is used to calculate the total annual revenue $T A R_{B}$ calculated in (17). Instead, $T A C_{B}(16)$ is the investment costs including grid reinforcement costs. The infrastructure costs of the case B are: the chargers, the new transformer of $500 \mathrm{kVA}$, new lines for the connection to the MV grid as well as the installation costs. Instead, $T A R_{B}$ uses the EV daily demand to calculate the total annual revenue based on the annual energy consumed by the users. When $T A C_{B}$ and $T A R_{B}$ are defined, $P B P, I R R, N P V$, and $B / C$ ratio can be calculated as shown in the proposed methodology.

Table 3 Cost - revenue calculation with BES 25000 cycles - case A

\begin{tabular}{|c|c|c|c|c|c|c|c|}
\hline $\begin{array}{l}\text { EVs daily } \\
\text { demand }\end{array}$ & $\begin{array}{c}\text { Capacity fade } \\
\text { per year [\%] } \\
B E S C F\end{array}$ & $\begin{array}{c}\text { Invest. costs } \\
{[€]} \\
T A C_{A}\end{array}$ & $\begin{array}{c}\text { Year benefits } \\
{[€]} \\
T A R_{A}\end{array}$ & $\begin{array}{c}P B P \\
\text { [years] }\end{array}$ & $\begin{array}{l}I R R \\
{[\%]}\end{array}$ & $\begin{array}{c}N P V \\
{[€]}\end{array}$ & $B / C$ ratio \\
\hline 35 & 1.4672 & -396064 & 68788 & 5.76 & $16.6 \%$ & 538794 & 2.45 \\
\hline 70 & 2.9345 & -475227 & 137577 & 3.45 & $28.8 \%$ & 1394488 & 4.09 \\
\hline 140 & 5.8691 & -633568 & 275154 & 2.30 & $43.4 \%$ & 3105862 & 6.14 \\
\hline 210 & 8.8037 & -791909 & 412731 & 1.92 & $52.1 \%$ & 4817237 & 7.37 \\
\hline 280 & 11.738 & -950250 & 550308 & 1.73 & $57.9 \%$ & 6528611 & 8.19 \\
\hline 350 & 14.672 & -1108591 & 687885 & 1.61 & $62.0 \%$ & 8239986 & 8.77 \\
\hline 420 & 17.607 & -1266918 & 825462 & 1.53 & $65.2 \%$ & 9951374 & 9.21 \\
\hline 490 & 20.542 & -1425259 & 963038 & 1.48 & $67.6 \%$ & 11662748 & 9.55 \\
\hline
\end{tabular}


Table 4 Cost - revenue calculation with BES 30000 cycles - case A

\begin{tabular}{|c|c|c|c|c|c|c|c|}
\hline $\begin{array}{l}\text { EVs daily } \\
\text { demand }\end{array}$ & $\begin{array}{c}\text { Capacity fade } \\
\text { per year [\%] } \\
B E S C F\end{array}$ & $\begin{array}{c}\text { Investment cost } \\
{[€]} \\
T A C A\end{array}$ & $\begin{array}{c}\text { Year benefits } \\
{[€]} \\
\text { TARA }\end{array}$ & $\begin{array}{c}P B P \\
\text { [years] }\end{array}$ & $\begin{array}{l}I R R \\
{[\%]}\end{array}$ & $\begin{array}{c}N P V \\
{[€]}\end{array}$ & $B / C$ ratio \\
\hline 35 & 1.2227 & -382867 & 68788 & 5.57 & $17.2 \%$ & 551990 & 2.54 \\
\hline 70 & 2.4454 & -448848 & 137577 & 3.26 & $30.5 \%$ & 1420867 & 4.33 \\
\hline 140 & 4.8909 & -580797 & 275154 & 2.11 & $47.4 \%$ & 3158634 & 6.70 \\
\hline 210 & 7.3364 & -712745 & 412731 & 1.73 & $57.9 \%$ & 4896400 & 8.18 \\
\hline 280 & 9.7819 & -844694 & 550308 & 1.53 & $65.1 \%$ & 6634167 & 9.21 \\
\hline 350 & 12.227 & -976642 & 687885 & 1.42 & $70.4 \%$ & 8371934 & 9.96 \\
\hline 420 & 14.672 & -1108591 & 825462 & 1.34 & $74.5 \%$ & 10109701 & 10.52 \\
\hline 490 & 17.118 & -1240539 & 963038 & 1.29 & $77.6 \%$ & 11847468 & 10.97 \\
\hline
\end{tabular}

Table 5 Cost - revenue calculation connection to MV grids - case B

\begin{tabular}{lcccccc}
\hline $\begin{array}{l}\text { EVs daily } \\
\text { demand }\end{array}$ & $\begin{array}{c}\text { Investment cost }[€] \\
T A C B\end{array}$ & $\begin{array}{c}\text { Year benefits } \\
{[€]}\end{array}$ & $\begin{array}{c}P B P \\
\text { TyRB }\end{array}$ & $\begin{array}{c}I R R \\
{[\%]}\end{array}$ & $\begin{array}{c}N P V \\
{[€]}\end{array}$ & $\begin{array}{c}B / C \text { ratio } \\
\text { [years] }\end{array}$ \\
\hline 35 & & 68788 & 11.56 & $5.9 \%$ & 139858 \\
70 & -795000 & 137577 & 5.78 & $16.5 \%$ & 1074715 & 2.45 \\
140 & -795000 & 275154 & 2.89 & $34.5 \%$ & 2944431 \\
210 & -795000 & 412731 & 1.93 & $51.9 \%$ & 4814146 & 7.34 \\
280 & -795000 & 550308 & 1.44 & $69.2 \%$ & 6683861 & 9.78 \\
350 & -795000 & 687885 & 1.16 & $86.5 \%$ & 8553576 & 12.23 \\
420 & -795000 & 825462 & 0.96 & $103.8 \%$ & 10423292 & 14.68 \\
490 & -795000 & 963038 & 0.83 & $121.1 \%$ & 12293007 & 17.12 \\
& -795000 & & & & \\
\hline
\end{tabular}

\section{Conclusions}

In this paper, the configuration and an optimal design of BESs within fast-charging stations were outlined. The work presented in this paper can help to understand the business model behind the use of different storage systems within context of DCFCSs. It was confirmed that reduction of the battery costs could present a profitable solution for the proposed DCFCS in certain scenarios. Simulation results showed that operation of DCFCS could be partially decoupled from the LV grid by introducing intermediate BESs with the advantage of minimizing the grid impact, the installation costs as well as the grid reinforcement costs. First of all, the DCFCS keeps the charging power constant during peak demand. Second, thanks to the BESs and the AC/DC $\mathrm{DC} / \mathrm{DC}$ converters the required power in $\mathrm{LV}$ grid is reduced by $28.57 \%$. Moreover, DCFCSs support more than $100 \mathrm{~km}$ of driving range within less than 10 minutes of charging.

In this study, the optimal size of the BESs within DCFCSs was a trade-off between the grid constraints and the EVs energy demand. A financial assessment for the proposed solution was performed, and the payback period, internal rate of return, net present value and benefit-cost ratio were considered in order to evaluate the financial performance of the five case studies. The financial performance of the case A, BES within the DCFCSs was crucially dependent on the life cycle cost of the batteries; on the contrary, the case B, MV connection was closely linked to the load demand presented by the EVs. The results of the case A showed that the number of battery replacements affects the main economic parameters significantly on the financial performance.

The finding of the financial assessment suggested the following: Case A: using batteries with low cycles such as 5000 or 10000 (NMC) are not economically viable because the investment holds the perspective of a continuous battery replacement costs. Instead, batteries with large number of cycles 25000-30000 (LTO) have the benefit-cost ratio higher than the Case B as long as the EVs daily demand is between 35 and 250 EVs. The case B has illustrated that the profitability of the investment increases if and only if the EVs penetration corresponds to more than $250 \mathrm{EVs}$ per day.

\section{References}

[1] Fernando S., 'Lithium-Ion Batteries: Fundamentals and Applications', IEEE Industrial Electronics Magazine, 2016

[2] Kassing P., Sumper A., Müller T., Heißwolf M., 'Battery Storage Systems Feasibility Study for Revenue Models in Germany', IEEE, 2017

[3] Nykvist, B., Nilsson M.: 'Rapidly falling costs of battery packs for electric vehicles ', Nature Climate Change 5.4, IEEE conference, 2015

[4] Nordhavn project; 'Design - dimensioning of the energy infrastructure of future sustainable cities', http://www.energylabnordhavn.dk, 2018 
[5] Papadaskalopoulos D., Strbac G., Nonlinear and Randomized Pricing for Distributed Management of Flexible Loads IEEE transactions on smart grid, 2016

[6] Behboodi S., Chassin D., Crawford C., 'Electric Vehicle Participation in Transactive Power Systems Using Realtime Retail Prices', IEEE International Conference, 2016

[7] IEC 61851: 'Conductive charging system / DC EV charging station', version 2017

[8] International Energy Agency's 'Nordic Electric Vehicle Outlook', 2018

[9] Liu Z., Wu. Q., Nielsen A.H., Wang Y: 'Day-Ahead Energy Planning with 100\% Electric Vehicle Penetration in the Nordic Region by 2050', energies 2015

[10] Zenginis I., Vardakas J., Zorba N., Verikoukis C.: 'Performance Evaluation of a Multi-standard Fast Charging Station for Electric Vehicles', IEEE transactions on smart grid, 2017

[11] Tan J., Wang L.: 'Real-Time Charging Navigation of Electric Vehicles to Fast Charging Stations: A Hierarchical Game Approach', IEEE transactions on smart grid, 2017

[12] Liu Z., Wen F., Ledwich G.: 'Optimal Planning of Electric-Vehicle Charging Stations in Distribution Systems', IEEE Transactions on Power Delivery, 2013

[13] Jia L., Hu Z., Song Y., Luo Z.: 'Optimal Siting and Sizing of Electric Vehicle Charging Stations', IEEE International electric vehicle conference, 2012

[14] C. J. R. Sheppard, A. Harris, and A. R. Gopal: 'Costeffective siting of electric vehicle charging infrastructure with agent-based modeling', IEEE Trans. Transport. Electrific., vol. 2, no. 3, Jun. 2016

[15] Huo Y., Bouffard F., Joós G., 'An energy management approach for electric vehicle fast charging station', IEEE 2017

[16] Bai, S., Lukic, S. M.: 'Unified active filter and energy storage system for an MW electric vehicle charging station', IEEE Transactions on Power Electronics, 2013

[17] Negarestani S., Firuzabad M., Rastegar M., Ghahnavieh A.:'Optimal Sizing of Storage System in a Fast Charging Station for Plug-in Hybrid Electric Vehicles', IEEE transactions on transportation electrification, 2016

[18] EvolvDSO: 'Evaluation of the DSOs' role, current architectures and future regulatory frameworks', Rep., 2017

[19] Hannan M.A, Hoque M.M, Hussain A., Yusof Y., Ker P.J,: 'State-of-the-Art and Energy Management System of LithiumIon Batteries in Electric Vehicle Applications: Issues and Recommendations', IEEE Access, 2018

[20] IEC 15118: 'Vehicle to grid communication interface', version 2016

[21] IEC 62196: 'Connectors for conductive charging of electric vehicles', version 2016

[22] Clement-Nyns, K., Haesen, E., Driesen, J.: 'The impact of vehicle-to-grid on the distribution grid', Electric Power Systems Research, 2011, 81, (1), pp. 185-192

[23] Hu, J., You, S., Lind, M., Ostergaard, J.: 'Coordinated charging of electric vehicles for congestion prevention in the distribution grid', IEEE Transactions on Smart Grid, 2014, 5, (2), pp. 703-711

[24] Knezović, K., Marinelli, M., Andersen, P. B., Træholt, C.: 'Concurrent provision of frequency regulation and overvoltage support by electric vehicles in a real Danish low voltage network', in Electric Vehicle Conference (IEVC), 2014 IEEE International, pp. 1-7

[25] Vardakas, J. S.: 'Electric vehicles charging management in communication controlled fast charging stations', in Computer Aided Modeling and Design of Communication Links and Networks (CAMAD), 2014, pp. 115-119

[26] 'Electric Vehicle Lab: Electric vehicle power system integration', http://www.powerlab.dk/Facilities/ElectricVehicle-Lab

[27] IEC61850: 'Communication/automation, Part 90-8: Object model for EV', 2017

[28] Johan G. Hayes, G Abas Goodarzi 'Electric Powertraction' energy system, power electronics and drives for Electric Vehicles, wiley, 2017

[29] 'GS Yuasa products', http://www.gsyuasalp.com/products.ht, 2017

[30] Setyawan L., Xiao J., Wang P.: 'Optimal Depth-ofDischarge Range and Capacity Settings for Battery Energy Storage in Microgrid Operation ', IEEE 2017

[31] Zhou B., Liu X., Cao Y., Li C., Chung Y.: 'Optimal scheduling of virtual power plant with battery degradation cost', IET generation, transmission\&distribution, 2015

[32] Xu B., Oudalov A., Ulbig A., Andersson G., Kirschen D.: 'Modeling of Lithium-Ion Battery Degradation for Cell Life Assessment', IEEE transactions on smart grid, 2018

[33] B. Kaun and S. Chen: 'Cost-Effectiveness of Energy Storage in California: Application of the Energy Storage Valuation Tool to Inform the California Public Utility Commission Proceeding R 10-12-007', EPRI, Palo Alto, CA: 2013. 3002001162.

[34] P. Balducci et al.: 'Assessment of Energy Storage Alternatives in the Puget Sound Energy System Volume 1: Financial Feasibility Analysis', PNNL, Richland, WA: 2013.

[35] Boardman, A., Greenberg, D., Vining, A. and Weimer, D.: 'Cost Benefit Analysis: Concepts and Practice', Prentice Hall, 4th Edition, 2018

[36] Duggal I., Bala Venkatesh B.: 'Short-Term Scheduling of Thermal Generators and Battery Storage With Depth of Discharge-Based Cost Model', IEEE transactions on power systems, 2015

[37] Rupolo D., Pereira B., Contreras J., Mantovani J. : 'Medium- and low-voltage planning of radial electric power distribution systems considering reliability', IET Generation, Transmission \& Distribution, 2017

[38] K. Knezović, M. Marinelli, P. Codani, and Y. Perez: 'Distribution Grid Services and Flexibility Provision by Electric Vehicles: a Review of Options', Universities Power Engineering Conference (UPEC), 2015 Proceedings of the 50th Intet., pp. 1-6, Staffordshire, 1-4 Sep. 2015

[39] ABB High-Power Electric Vehicle Fast Charging Station,http://www.abb.com/cawp/seitp202/c2ed43a8ef 2e1de2c12581ae002d26b8.aspx , 2018 